\title{
Facile Synthesis and Application of Ag-Chemically Converted Graphene Nanocomposite
}

\author{
Jianfeng Shen, Min Shi, Na Li, Bo Yan, Hongwei Ma, Yizhe Hu, and Mingxin Ye ( $₫$ ) \\ Center of Special Materials and Technology, Fudan University, Shanghai 200433, China \\ Received: 2 March 2010 / Revised: 15 March 2010 / Accepted: 15 March 2010 \\ (C) The Author(s) 2010. This article is published with open access at Springerlink.com
}

\begin{abstract}
An in situ chemical synthesis approach has been employed to prepare an Ag-chemically converted graphene (CCG) nanocomposite. The reduction of graphene oxide sheets was accompanied by generation of $\mathrm{Ag}$ nanoparticles. The structure and composition of the nanocomposites were confirmed by means of transmission electron microscopy (TEM), atomic force microscopy (AFM) and X-ray diffraction. TEM and AFM results suggest a homogeneous distribution of Ag nanoparticles (5-10 nm in size) on CCG sheets. The intensities of the Raman signals of CCG in such nanocomposites are greatly increased by the attached silver nanoparticles, i.e., there is surface-enhanced Raman scattering activity. In addition, it was found that the antibacterial activity of free Ag nanoparticles is retained in the nanocomposites, which suggests they can be used as graphene-based biomaterials.
\end{abstract}

\section{KEYWORDS}

graphene, graphene oxide, nanoparticle, silver

\section{Introduction}

As a one atom-thick sheet of $\mathrm{sp}^{2}$-bonded carbon atoms in a hexagonal two-dimensional lattice, graphene has rapidly become known as a highly promising nanomaterial with unique properties [1-13]. Due to its special physical and chemical properties, graphene has shown promise for several advanced technological applications, such as graphene-based composites, chemical detectors, fuel cells, and many others [14-28].

A number of different ways of preparing graphene have been reported [29-36]. Among these, nearly perfect graphene has been prepared by mechanical exfoliation, which has opened up the promising field of graphene-based electronics [29]. Nevertheless, it should be noted that this method is time consuming and the yield is extremely low, limiting its ability to have a significant economic and technological impact. It has been shown that graphene can also be prepared via solution chemistry involving oxidation of graphite to afford layered graphene oxide sheets (GOS) followed by a subsequent reduction [37-39]. GOS are chemically modified graphene sheets containing oxygen functional groups such as epoxide and carboxylic acid. They not only have a two-dimensional structure like graphene but also possess other properties totally different from graphene, such as hydrophilicity and controllable electronic properties. However, unless well separated from each other, as-prepared graphene sheets tend to form irreversible agglomerates or even restack to form

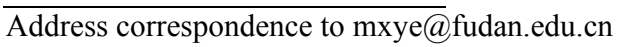


graphite through van der Waals interactions [40-43]. Therefore, the addition of a dispersant which can bind tightly onto graphene sheets is necessary in order to achieve better dispersions of the graphene. In this case, however, the removal or leaching of dispersants during the subsequent application of these graphene sheets are potential threats.

Recently, graphene/metal nanoparticle composites have aroused extensive interest and they are supposed to be useful in the fields of chemical sensors, energy storage, catalysis, and hydrogen storage [44-61]. The requirement to obtain graphene as individual sheets, and to maintain it in the reduced form, introduces complexity into the design of composite systems. In this work we propose a solution-based silver functionalization of graphene. The advantages of our method lie in the following: (1) we sought to use mixed reducing agents to enhance the reducing strength and make the reaction environment mild at the same time; (2) by controlling the strength of the reducing agent, the growth of $\mathrm{Ag}$ nanoparticles and reduction of GOS to chemically converted graphene (CCG) can be achieved simultaneously; (3) the formation of $\mathrm{Ag}$ nanoparticles on CCG can greatly reduce the degree of stacking of CCG nanosheets; (4) the prepared Ag-CCG nanocomposites have potential applications as surfaceenhanced Raman scattering (SERS) substrates and antibacterial materials.

\section{Experimental}

\subsection{Materials}

Expandable graphite (EG) was purchased from Qingdao BCSM Co., Ltd. All other reagents were at least of analytical reagent grade and used without further purification.

\subsection{Preparation of Ag-CCG}

EG was first treated at $1050{ }^{\circ} \mathrm{C}$ in air for $15 \mathrm{~s}$. The size was enlarged up to nearly 200 times its original amount in this way. Graphite oxide (GO) was obtained by the modified Hummers method as described elsewhere $[62,63] .50 \mathrm{mg}$ of $\mathrm{GO}$ was added to $30 \mathrm{~mL}$ of ethylene glycol. The above mixture was sonicated for $30 \mathrm{~min}$ followed by high-speed stirring for a further $1 \mathrm{~h}$ to give GOS. $200 \mathrm{mg}$ of $\mathrm{AgNO}_{3}$ was dissolved in $15 \mathrm{~mL}$ of ethylene glycol with $5 \mathrm{~mL}$ of $\mathrm{H}_{2} \mathrm{O}$. This mixture was then added to the mixture of GOS/ethylene glycol and kept at $50{ }^{\circ} \mathrm{C}$ for $2 \mathrm{~h} .40 \mathrm{~mL}$ of $0.1 \mathrm{~mol} / \mathrm{L}$ sodium borohydride $\left(\mathrm{NaBH}_{4}\right)$ solution was slowly added and the mixture was heated at $110{ }^{\circ} \mathrm{C}$ for $2 \mathrm{~h}$. When the reduction reaction was finished, the reaction mixture was filtered and the product washed three times with doubly distilled water and then dried in an oven at $80^{\circ} \mathrm{C}$ under vacuum. The fabrication process is outlined in Fig. 1.

\subsection{Instruments and measurement}

Fourier transform infrared spectroscopy (FTIR) spectra were recorded on a Nexus 670 spectrometer. Raman spectra were recorded on a Dilor LabRam-1B multichannel confocal microspectrometer with $514.5 \mathrm{~nm}$ laser excitation. Thermogravimetric analysis (TGA) was conducted with a Netzsch TG 209F1 instrument that was fitted with a nitrogen purge gas using a heating rate of $10{ }^{\circ} \mathrm{C} / \mathrm{min}$. Before the tests, all the samples were carefully ground to powders to ensure sufficient diffusion of heat. The measurements were conducted using 6-10 mg of samples and weight retention/ temperature curves were recorded. X-ray diffraction (XRD) patterns were recorded on a Rigaku D/max-rB diffractometer using $\mathrm{Cu} \mathrm{K \alpha}$ radiation. Transmission electron microscopy (TEM) was performed with a JEOL JEM-2100F microscope. Atomic force microscopy (AFM) images were obtained using a Multimode Nano4 in the tapping mode. Water bath sonication was performed with a JL-60 DTH sonicator ( $50 \mathrm{~W})$. Antibacterial activity tests were performed according to GB/T 21510-2008. Colibacillus, Staphylococcus aureus and Canidia albicans were grown in nutritional broth and stored at $0{ }^{\circ} \mathrm{C}$. The experiments were carried out in a biosafety cabinet and the concentration of Ag-CCG was $0.05 \mathrm{mg} / \mathrm{mL}$. The disinfection rate $R$ was calculated as follows:

$$
R=\frac{A-B}{B} \times 100 \%
$$

where $A$ is the average bacterial count with the reference sample and $B$ is the average bacterial count with the sample under test. 


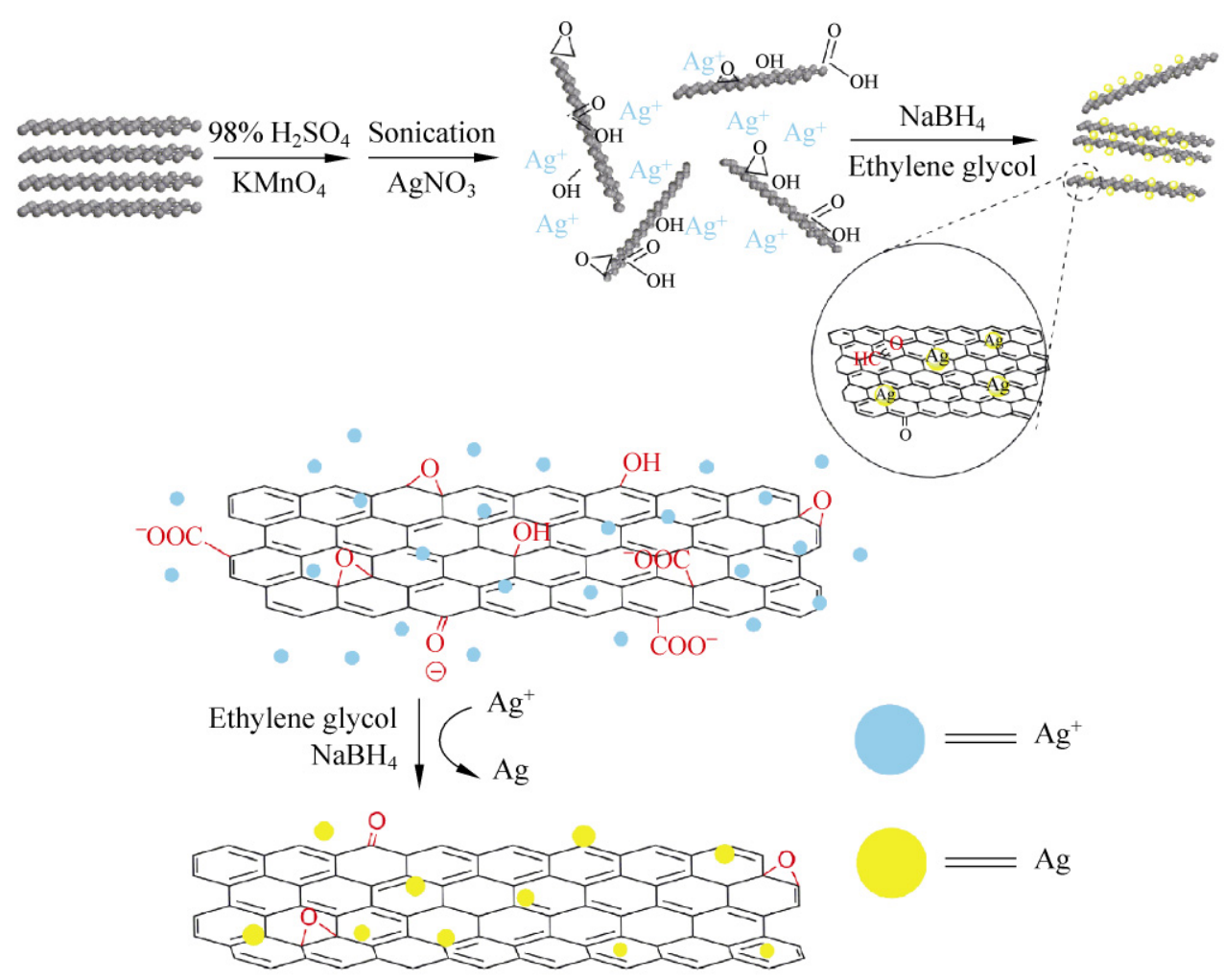

Figure 1 Experimental procedure used in this study

\section{Results and discussion}

Among known strategies for generating graphenebased materials, those based on utilization of GO are arguably the most versatile and easily scalable methods. GO is a strongly oxygenated, highly hydrophilic layered material that can be readily exfoliated in water to yield stable dispersions consisting mostly of single-layer GOS. These stable flexible GOS are usually used as the starting material for the preparation of graphene-based materials [38].

Ethylene glycol is a widely used reducing agent. It can not only work as a chelating agent but also serve as a reducing agent to convert metal ions into metal or alloy nanoparticles [64]. However, since ethylene glycol is only a mild reducing agent, it requires a long reaction time to reach completion. In this study, we overcome the shortcoming of ethylene glycol by the addition of a more active reducing agent, $\mathrm{NaBH}_{4}$. A little water was added during the reduction process to facilitate the exfoliation of GO. In addition, the water may buffer the formation rate of the metal particles, and give some control over particle size [65].
Figure 2 shows the FTIR spectra of GO and Ag-CCG. In the spectrum of $\mathrm{GO}$, the peak at $3450 \mathrm{~cm}^{-1}$ arises from the $-\mathrm{OH}$ stretching vibration. There are also bands due to carboxyl $\mathrm{C}=\mathrm{O}$ and $\mathrm{C}-\mathrm{O}$ groups (1650 and $\left.1400 \mathrm{~cm}^{-1}\right)$, epoxy $\mathrm{C}-\mathrm{O}\left(1200 \mathrm{~cm}^{-1}\right)$, and alkoxy C-O $\left(1100 \mathrm{~cm}^{-1}\right)$ groups situated at the edges of the GO nanosheets, as has been reported previously [66]. In contrast, these bands are almost entirely absent in the spectrum of Ag-CCG. The loss of intensity of the peak at $3450 \mathrm{~cm}^{-1}$ confirms the involvement and reduction of oxygen-containing groups in the formation of the Ag nanoparticles. Besides, it also suggests that strong interactions may exist between the $\mathrm{Ag}$ nanoparticles and the remaining surface hydroxyl $O$ atoms [67]. Interestingly, the interactions between the nanoparticles and CCG were strong enough to ensure the nanoparticles remained attached even after chemical cleaning and ultrasonication.

Raman spectroscopy is a non-destructive optical technique. It has been successfully used to characterize graphene and other carbon-based materials and it can also provide useful information about the crystallinity and the number of layers present in the 


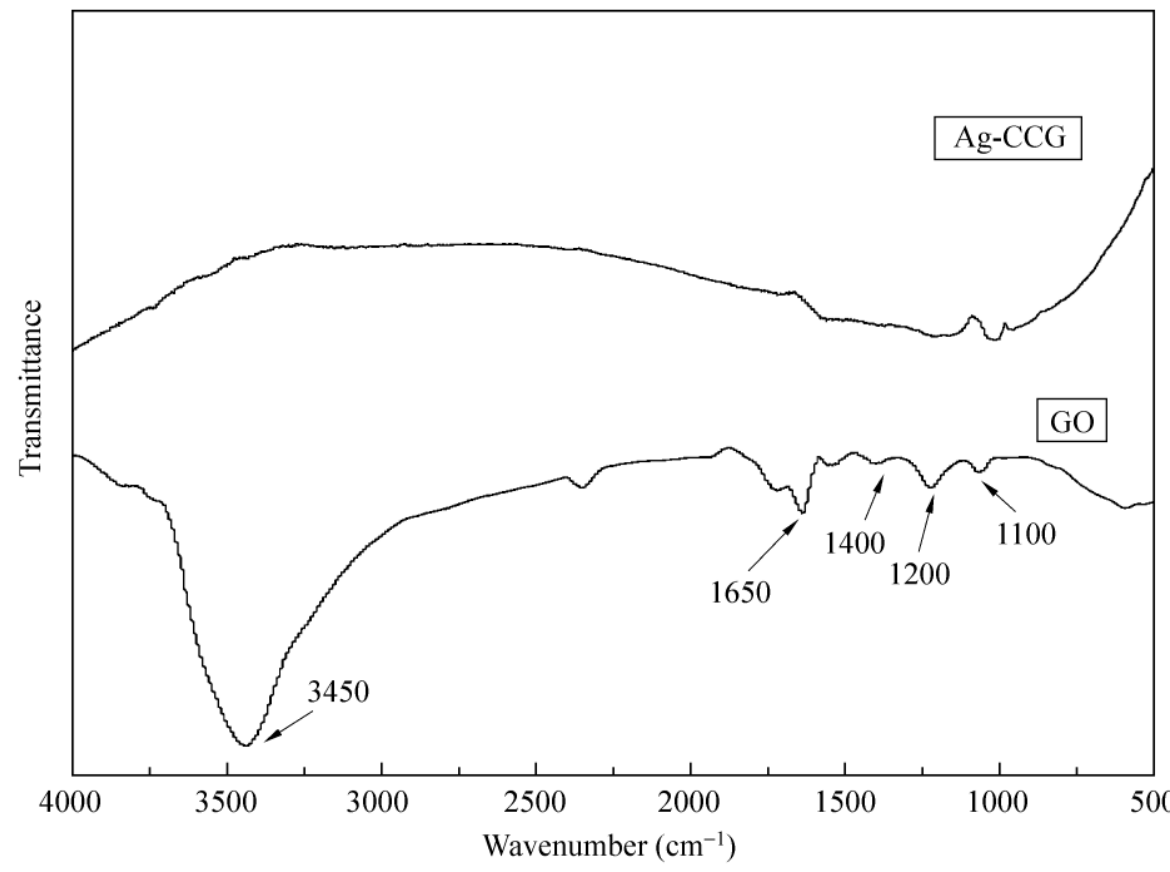

Figure 2 FTIR spectra of GO and Ag-CCG sample [32]. As can be seen in Fig. 3, there are two characteristic peaks, namely, the D band at $1330 \mathrm{~cm}^{-1}$ and the $\mathrm{G}$ band at $1580 \mathrm{~cm}^{-1}$. The $\mathrm{D}$ band is ascribed to edges, other defects, and disordered carbon, whereas the $G$ band arises from the zone center $E_{2 g}$ mode, corresponding to ordered $\mathrm{sp}^{2}$-bonded carbon atoms. Compared with raw graphite, after oxidation the $\mathrm{D}$ mode of $\mathrm{GO}$ becomes stronger and broader and there is a clear increase in the ratio of the intensity of the D-band to that of the G-band (the $R$-value). The $R$-value is a measure of the degree of disorder and average size of the $\mathrm{sp}^{2}$ domain. The increased value suggests that the oxidation process results in a higher level of disorder of the graphene layers and an increased number of defects. Besides, a slight frequency shift (about $10 \mathrm{~cm}^{-1}$ ) toward a higher wavenumber and a broadened bandwidth of the G-band are found in GO compared with graphite, indicating a decrease in the in-plane size of graphene during the chemical reaction process. The $R$-value for Ag-CCG is slightly greater than that of GO. This change suggests a decrease in the average size upon reduction of the exfoliated GO. It is reasonable to consider that the reduction of GO causes some fragmentation along the reactive sites and yields new graphitic domains, which leads to graphenes smaller in size, but more numerous in number, compared to $\mathrm{GO}$ before reduction. Even though the intensity of the $\mathrm{D}$ band is associated with defects, in the case of graphene it has also been observed that there is a substantial contribution from the edge effects [32]. The Raman spectra described above are consistent with a previous report [17]. Taken together with the TEM and AFM results (see below), Raman spectroscopy confirms that Ag-CCG was greatly exfoliated. The strong $\mathrm{D}$ band in the Raman spectrum of Ag-CCG arises mostly from the edges and steps present in the graphene.

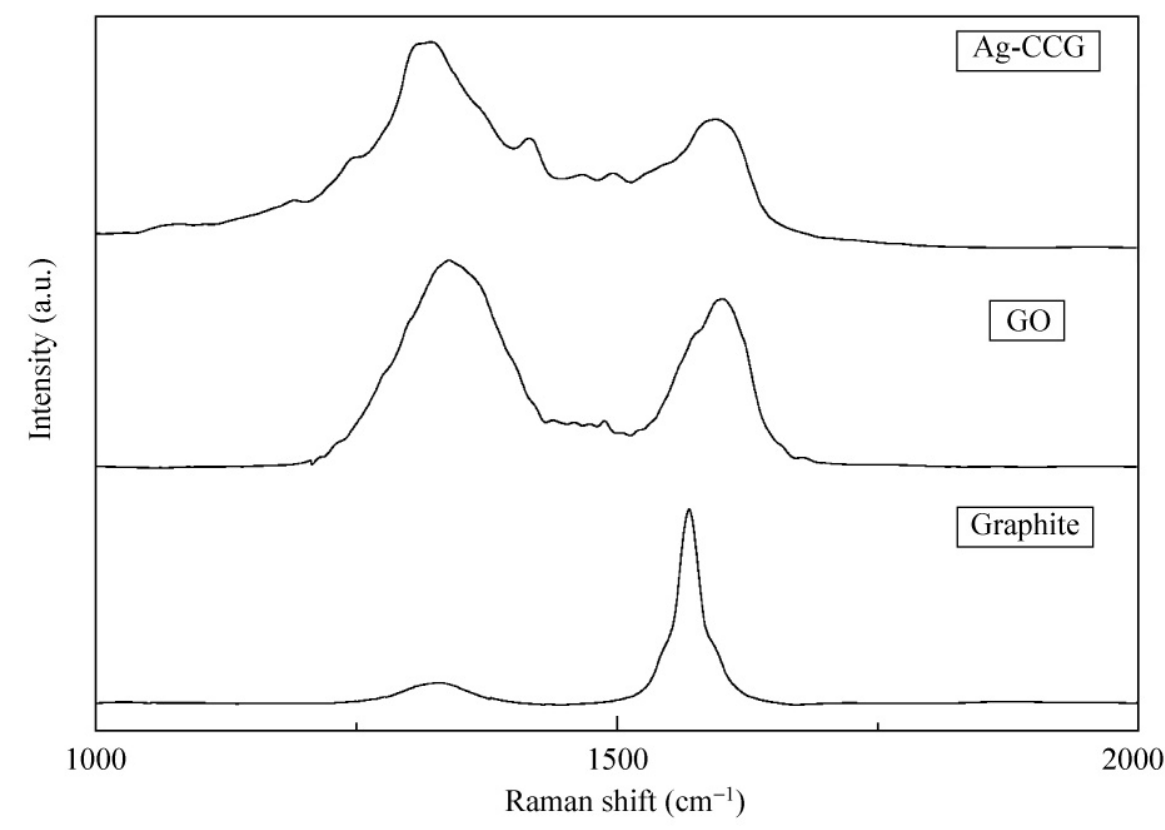

Figure 3 Raman spectra of graphite, GO and Ag-CCG 
The successful functionalization of CCG sheets with Ag nanoparticles was also reflected in the TGA curves. As shown in Fig. 4, GO shows much lower thermal stability than the raw graphite. The main weight loss takes place around $200-400{ }^{\circ} \mathrm{C}$, presumably due to pyrolysis of the labile oxygen-containing functional groups. Besides, the onset temperature becomes dramatically lower and there is also a mass loss $(\sim 3 \%)$ below $100{ }^{\circ} \mathrm{C}$ attributed to the removal of adsorbed water. The reason for the much lower thermal stability is easy to understand: GO has a layered morphology with oxygen-containing functionality, which will disrupt the hexagonal carbon basal planes on the interior of the multilayered stacks of GOS, thus accelerating the process of weight loss. Compared with GO, the weight loss of the Ag-CCG nanocomposites below $200{ }^{\circ} \mathrm{C}$ is much lower, indicating that main oxygen-containing functional groups of GO has been converted after reduction. Moreover, the weight loss associated with high temperature pyrolysis of Ag-CCG around $650{ }^{\circ} \mathrm{C}$ is similar to that for graphite, and results from pyrolysis of the carbon skeleton of CCG [68].

The crystal structure and particle size distribution of Ag-CCG were characterized by XRD. The XRD patterns of graphite and GO were recorded for comparison (Fig. 5). A diffraction peak at $23^{\circ}-27^{\circ}$ is attributed to

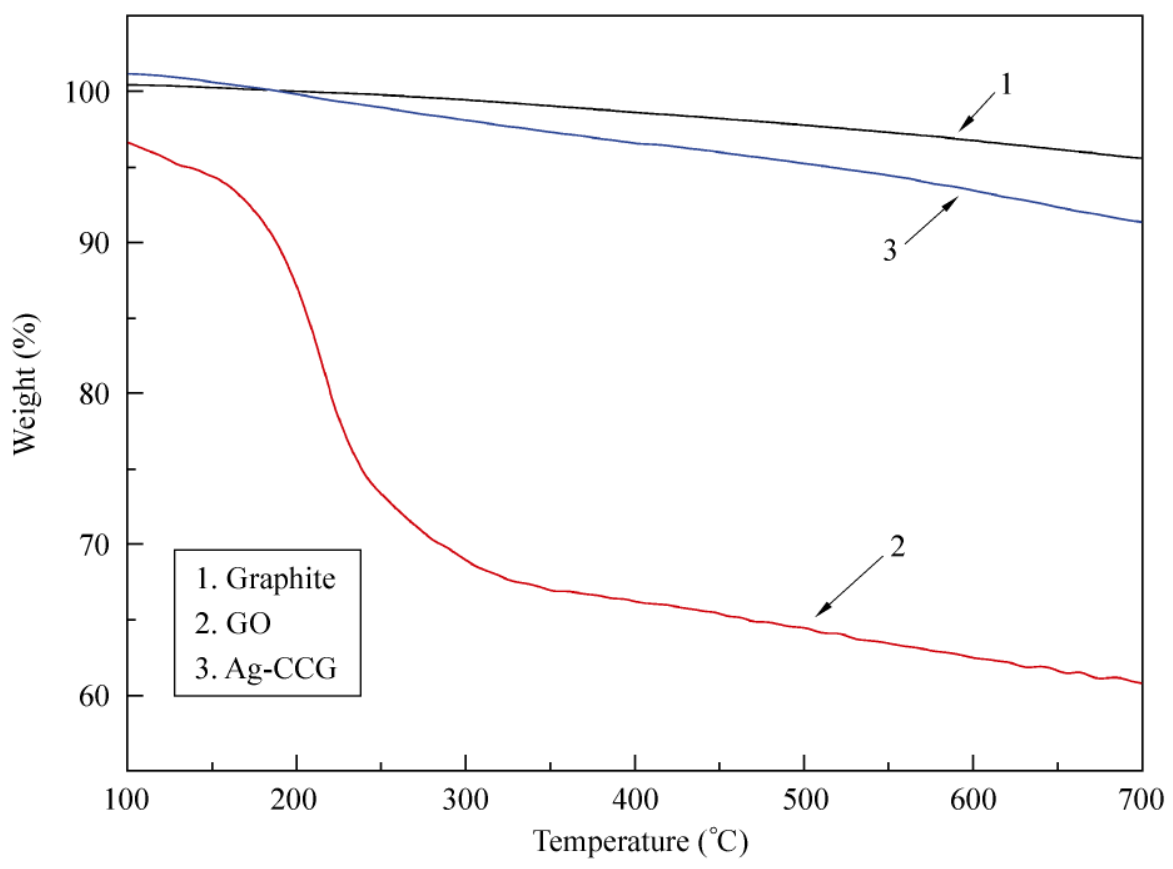

Figure 4 TGA curves of graphite, GO and Ag-CCG the (002) reflection of a hexagonal graphite structure and its intensity can reflect the degree of graphitization of a carbon material. Raw graphite shows a very strong 002 peak at $26.44^{\circ}$. For GO, while a small change in the position of the principal reflection is observed, the most striking difference is the intensity and broadness of the peak (observed at $2 \theta=22.84^{\circ}$ ), corresponding to an average interlayer spacing of $\sim 0.4 \mathrm{~nm}$. The expansion of the $\mathrm{d}$-spacing relative to that of graphite is ascribed to the oxygen-containing groups and inserted $\mathrm{H}_{2} \mathrm{O}$ molecules. By virtue of the presence of oxygen-containing functional groups attached on both sides of the graphene sheet, as well as the atomic scale roughness arising from structural defects $\left(\mathrm{sp}^{3}\right.$ bonding) generated on the originally atomically flat graphene sheets, individual GOS are expected to be thicker than individual pristine graphene sheets. In addition, the broad diffraction peak of the GO powder suggests that the functionalization process can influence the crystallinity of the samples. The major diffraction lines in the powder pattern of Ag-CCG can be indexed to the Ag face centered cubic (fcc) phase. The relatively broad diffraction peaks of Ag indicate relatively small crystal size. The average particle size of the deposited Ag nanoparticles was calculated to be ca. $8 \mathrm{~nm}$ from the (111), (200), and (220) X-ray diffraction peaks based on Scherrer's equation. No obvious diffraction peaks of GO were observed in the as-synthesized composite, which is consistent with complete exfoliation of CCG. In addition, the peaks between $15^{\circ}$ and $30^{\circ}$ are down-shifted and broadened compared with the corresponding peaks for GO. The broad nature of the reflection indicates poor ordering of the sheets along the stacking direction, implying that the samples are composed of mostly single or few layers of CCG [50].

To further characterize the exact structures of the nanocarbons in the dispersions, we conducted TEM analysis. TEM samples were 


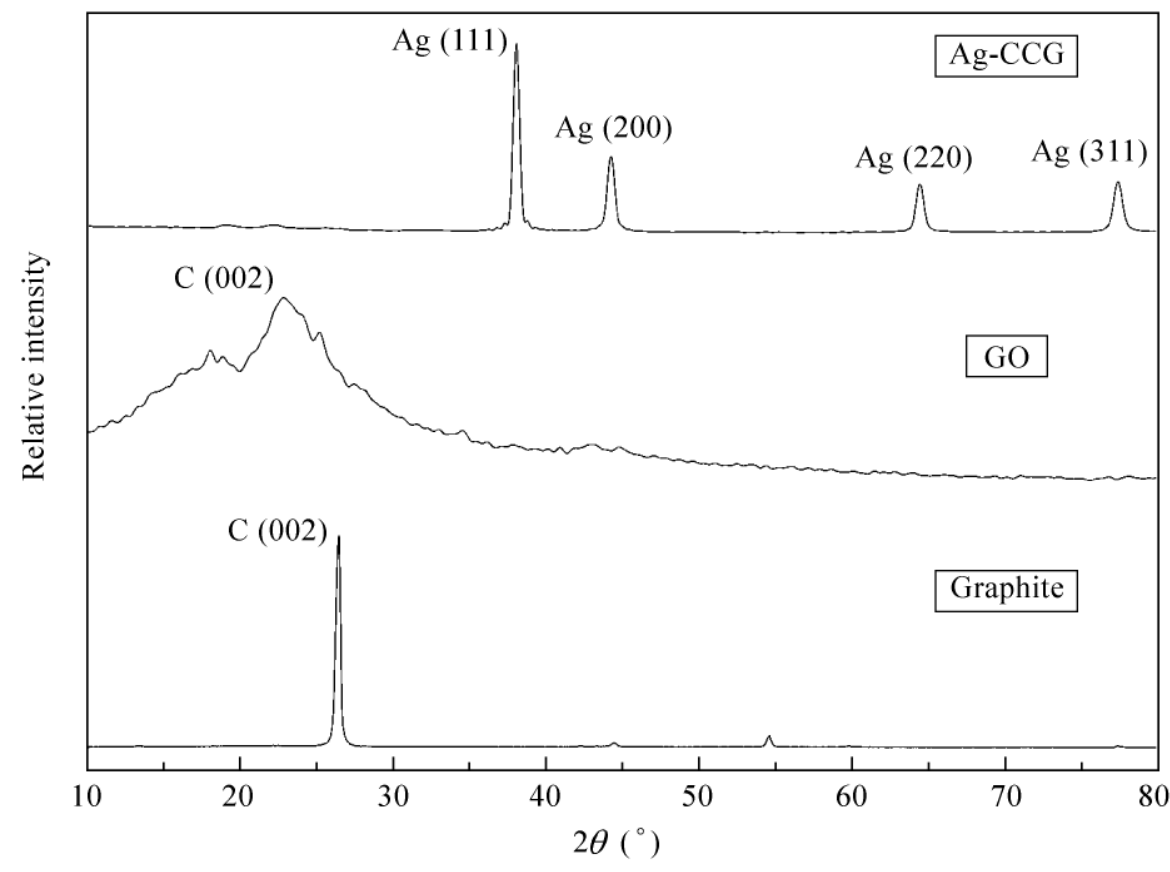

Figure 5 XRD patterns of graphite, GO and Ag-CCG

prepared by pipetting a few milliliters of dispersion onto holey carbon mesh grids. From the TEM image of raw graphite (Fig. 6(a)), we find that even after ultrasonication, graphite cannot be exfoliated and the flakes are dark, thick, and large, showing the original graphitic structure was retained. In the case of GO (Fig. 6(b)), large sheets (a few hundred square nanometers) were observed on the top of the grid, where they were entangled with each other and resembled silk veil waves. During the reduction process, the color of the suspension changed from brown to black, which further confirms the change from GO to CCG sheets. A typical TEM image of Ag-CCG (Fig. 6(c)) illustrates that almost all the CCG sheets are separated from each other and coupled by Ag nanoparticles. The almost transparent carbon sheets were thickly covered by the silver nanoparticles and few particles were scattered outside the CCG sheets. Since the monolayer carbon nanosheets are extremely thin, it is hard to make a distinction between them and the carbon-supported films on the copper grid. However, the edges and crumpled silk waves of these carbon sheets (indicated by arrows in Fig. 6(c)) lead us to believe that these nanoparticles are indeed deposited on supports-the almost transparent graphene sheets. Besides, in comparison with GO, the surface of CCG is much rougher, which can be attributed to the growth of Ag nanoparticles on CCG sheets [69]. The in situ reduction process allows these nanoparticles of metallic silver (as shown in the high-resolution TEM (HRTEM) image in Fig. 6(d)) to attach onto the CCG sheets. The average size of the Ag nanoparticles is about $6 \mathrm{~nm}$.

We also employed AFM to establish the thickness and surface roughness of the depositions, since AFM characterization has been one of the most direct methods of quantifying the degree of exfoliation of graphene after dispersion of the powder in a solvent. The samples were prepared by depositing the corresponding dispersion on highly orientated pyrolytic graphite (HOPG) and drying in air. Since the basal planes of the graphene sheets in GO are decorated mostly with oxygen- containing moieties - such as epoxide, hydroxyl, carbonyl, and carboxyl groups-these oxygen functionalities will alter the van der Waals interactions between the layers and make them hydrophilic, thus facilitating their exfoliation in aqueous media. As a consequence, GO readily forms stable colloidal dispersions of thin GO sheets in water. We found that sufficiently dilute colloidal suspensions of GO prepared with the aid of ultrasound are homogeneous and stable. AFM images confirm that the evaporated dispersion of GO is comprised of isolated graphitic sheets (Fig. 7(a)). The cross-sectional view of a typical AFM image of the exfoliated GO shows that its thickness is about $1.2 \mathrm{~nm}$, indicating the full exfoliation of GO [40, 70]. From Fig. 7(b) we can see that CCG sheets are thickly covered by the silver nanoparticles and the average size of Ag nanoparticles is about $10 \mathrm{~nm}$, which is consistent with the TEM results.

Although the mechanism of the reduction reaction is still unclear, we tentatively speculate that the whole process may contain three steps. (1) The presence of oxygen functionalities at the graphene surface provides 

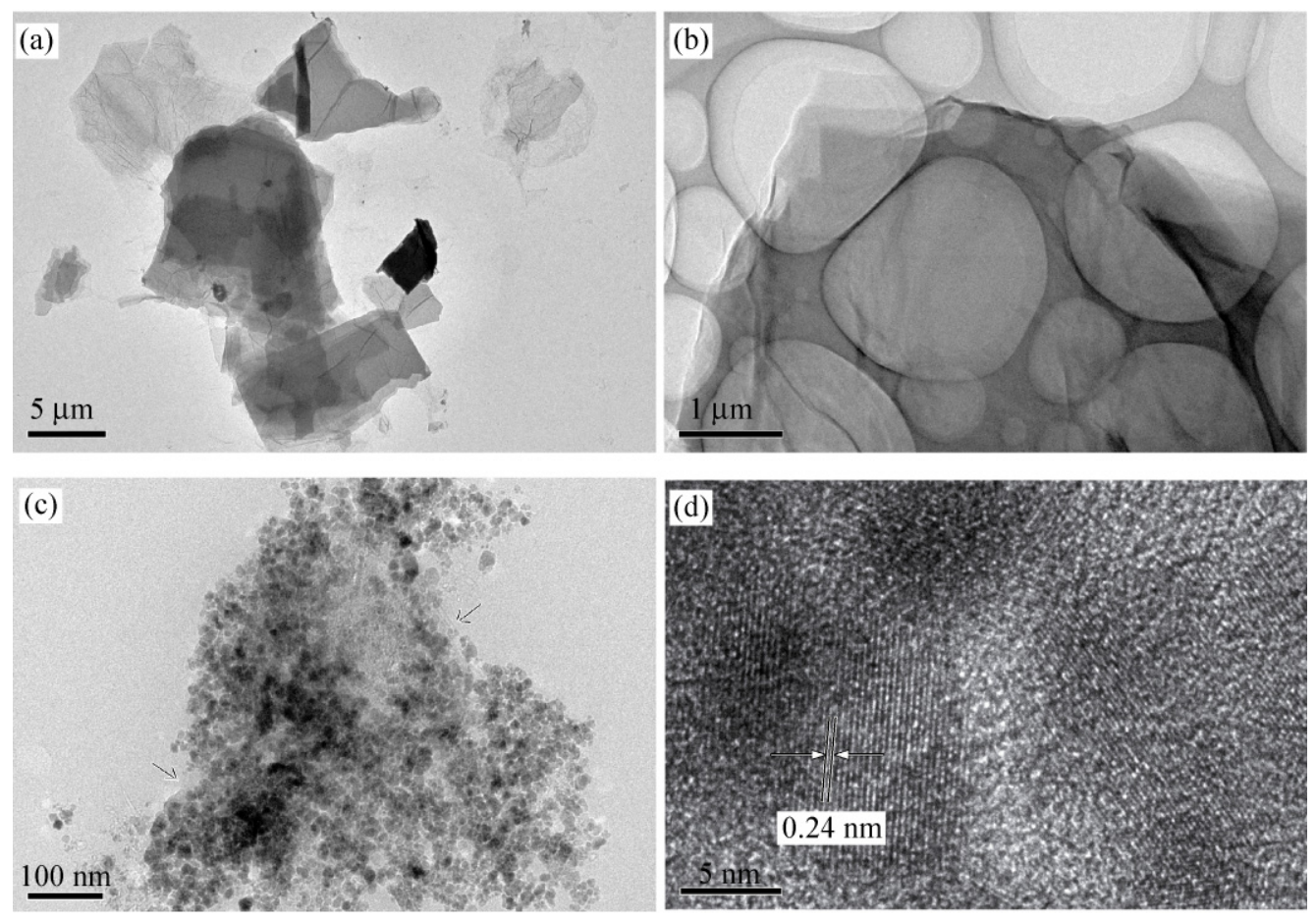

Figure 6 Representative TEM images of graphite (a), GO (b), and Ag-CCG ((c) and (d))
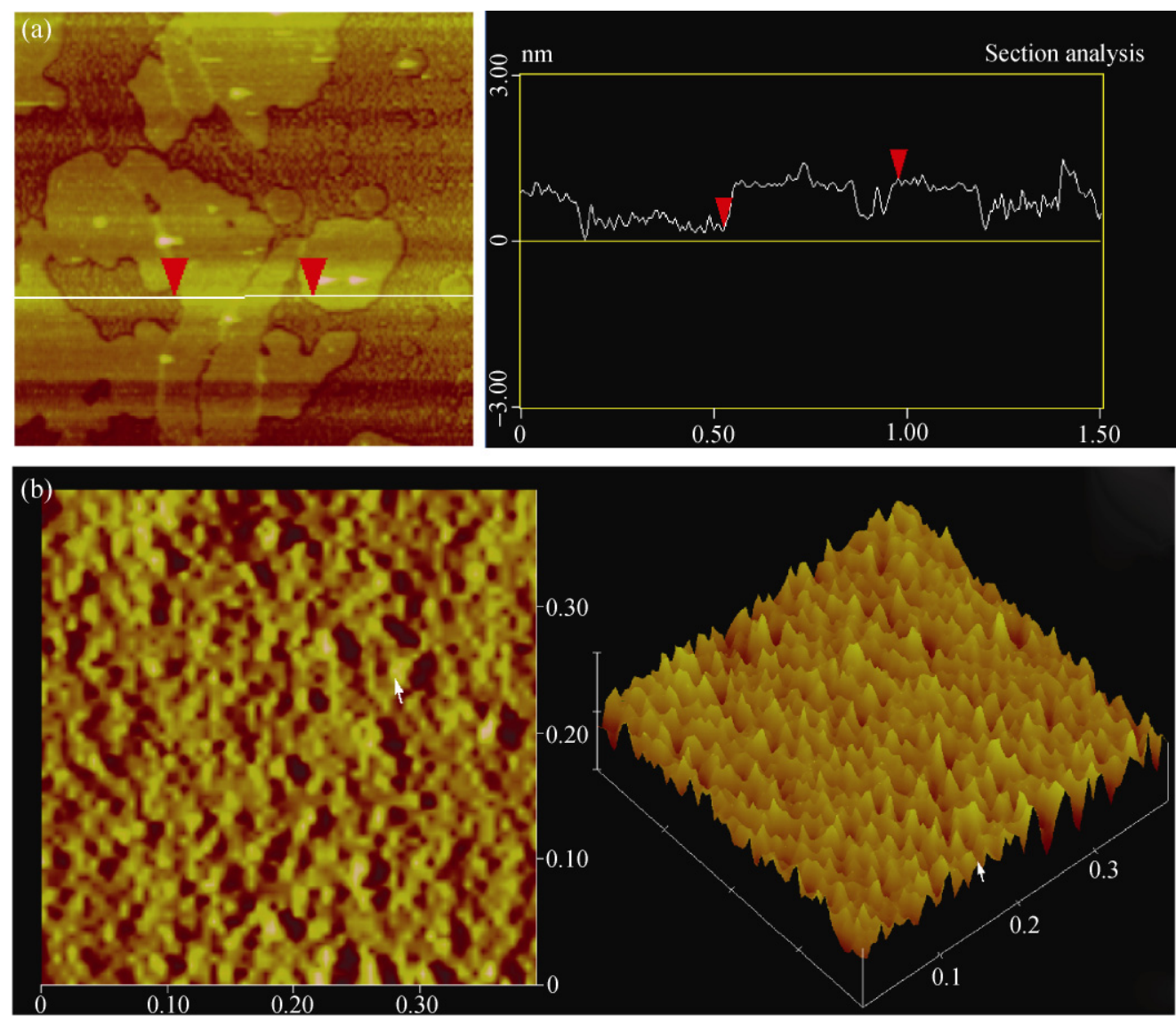

Figure 7 AFM images of GOS (a) and Ag nanoparticles on Ag-CCG (b), with concentration of $0.05 \mathrm{mg} / \mathrm{mL}$. Image dimensions are $1.5 \mu \mathrm{m} \times 1.5 \mu \mathrm{m}$ and $0.4 \mu \mathrm{m} \times 0.4 \mu \mathrm{m}$, respectively 
reactive sites for the nucleation of silver nanoparticles. It has been reported that the mechanism of nucleation and growth of silver nanoparticles depends on the degree of oxygen functionalization at the graphene surface sheets and the nucleation of silver nanoparticles at GO surfaces is mainly governed by the presence of oxygen groups at GO [59]. Although it is not possible to make a distinction between the roles of each oxygen group present on the GO surface on the nucleation of Ag nanoparticles, it is believed that the oxygen functional groups are responsible for the initial attachment of the free $\mathrm{Ag}^{+}$ions in solution by electrostatic interactions. Meanwhile, the ability to exfoliate GO into single sheets provides a relatively large area on which to disperse the silver particles. Although a large number of silver particles are adsorbed on these GOS, the resulting composite can be dispersed in water by sonication, forming a stable suspension. (2) When $\mathrm{Ag}^{+}$is reduced by the addition of a mixture of ethylene glycol and $\mathrm{NaBH}_{4}$, the growth of Ag particles begins and they will stay attached to the GOS. (3) The additional reduction of GOS to CCG is observed provided that the reducing agent is strong enough, forming Ag-CCG nanocomposites. In addition, the adhered Ag nanoparticles could inhibit the aggregation of graphene sheets while drying [70].
SERS occurs when molecules are adsorbed on nanostructured surfaces, nanoparticles, or rough electrodes of noble metals and it is one of the most powerful microanalytical techniques with single-molecule capabilities and chemical specificity. Different types of SERS substrates have been developed involving either pure or supported nanostructured metals, mostly gold and silver. Research has shown that silver nanoparticle films are excellent substrates for SERS for molecular sensing with high sensitivity and specificity [50]. Raman spectra were recorded with $514.5 \mathrm{~nm}$ laser excitation. We found that the as-synthesized Ag-CCG displayed SERS activity. It can be seen that the enhancement factors of the characteristic peaks of CCG (D and G bands) appear to be about three orders of magnitude (Fig. 8). This finding provides a feasible means to study some characteristics of graphene-based materials in detail using SERS.

It was previously shown that graphene and GO are biocompatible materials [24]. Thus, it is possible to use Ag-CCG as an antibacterial material. The results of antibacterial tests (Table 1 ) show that when the concentration of Ag-CCG was $0.05 \mathrm{mg} / \mathrm{mL}$, the bacterial cultures (Colibacillus, Staphylococcus aureus and Canidia albicans) were almost completely destroyed, showing the high disinfection ability of Ag-CCG.

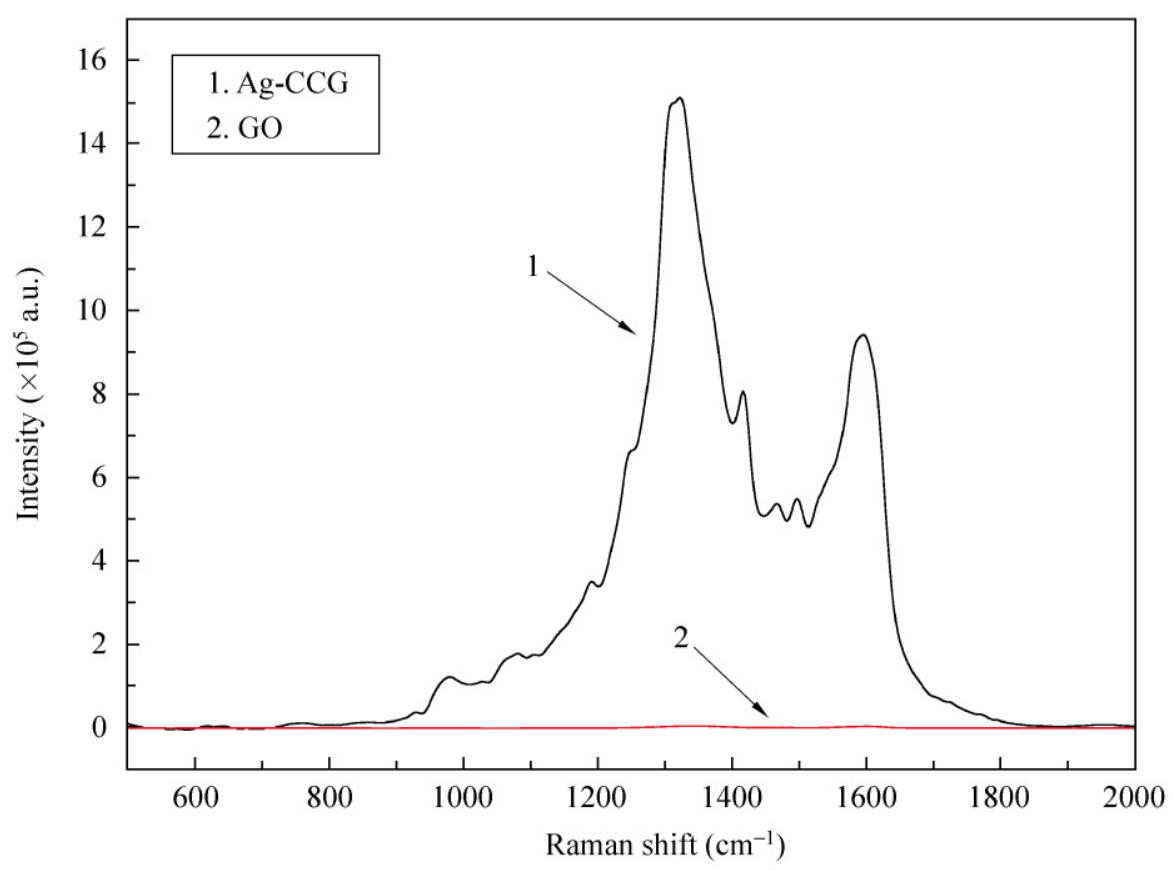

Figure 8 SERS spectra of Ag-CCG 
Table 1 Antibacterial activity tests of Ag-CCG

\begin{tabular}{lccc}
\hline Bacterial culture & $\begin{array}{c}0 \text { min colony } \\
\text { counting }\end{array}$ & $\begin{array}{c}36 \text { h colony } \\
\text { counting }\end{array}$ & $\begin{array}{c}\text { Disinfection } \\
\text { rate }(\%)\end{array}$ \\
\hline Colibacillus & $5 \times 10^{8}$ & $10 \times 10^{5}$ & 99.80 \\
$\begin{array}{l}\text { Staphylococcus } \\
\text { aureus }\end{array}$ & $5 \times 10^{8}$ & $8 \times 10^{5}$ & 99.84 \\
Canidia albicans & $5 \times 10^{8}$ & $12 \times 10^{5}$ & 99.76 \\
\hline
\end{tabular}

\section{Conclusions}

Graphene-metal nanohybrid assemblies can be prepared in a solution-based approach involving the chemical reduction of silver ions in CCG suspensions with mixed reducing agents. Our studies indicate that the resulting Ag-CCG nanocomposites are potential substrates for SERS studies. In addition, it was found that the antibacterial activity of free Ag nanoparticles is retained, which suggests the materials may be used as graphene-based biomaterials.

Open Access: This article is distributed under the terms of the Creative Commons Attribution Noncommercial License which permits any noncommercial use, distribution, and reproduction in any medium, provided the original author(s) and source are credited.

\section{References}

[1] Rao, C. N. R.; Biswas, K.; Subrahmanyam, K. S.; Govindaraj, A. Graphene, the new nanocarbon. J. Mater. Chem. 2009, 19, 2457-2469.

[2] Sykes, E.; C. H. Surface assembly. Graphene goes undercover. Nat. Chem. 2009, 1, 175-176.

[3] Wu, J. S.; Pisula, W.; Müllen, K. Graphenes as potential material for electronics. Chem. Rev. 2007, 107, 718-747.

[4] Rao, C. N. R.; Sood, A. K.; Subrahmanyam, K. S.; Govindaraj, A. Graphene: The new two-dimensional nanomaterial. Angew. Chem. Int. Ed. 2009, 48, 7752-7777.

[5] Zhu, J. Graphene production: New solutions to a new problem. Nat. Nanotech. 2008, 3, 528-529.

[6] Novoselov, K. S.; Geim, A. K.; Morozov, S. V.; Jiang, D.; Zhang, Y.; Dubonos, S. V.; Grigorieva, I. V.; Firsov, A. A. Electric field effect in atomically thin carbon films. Science 2004, 306, 666-669.

[7] Geim, A. K.; Novoselov, K. S. The rise of graphene. Nat. Mater. 2007, 6, 183-191.

[8] Ni, Z. H.; Wang, H. M.; Kasim, J.; Fan, H. M.; Yu, T.; Wu, Y.
H.; Feng, Y. P.; Shen, Z. X. Graphene thickness determination using reflection and contrast spectroscopy. Nano Lett. 2007, 7, 2758-2763.

[9] Liu, H. T.; Ryu, S. Y.; Chen, Z.; Steigerwald, M. L.; Nuckolls, C.; Brus, L. E. Photochemical reactivity of graphene. J. Am. Chem. Soc. 2009, 131, 17099-17101.

[10] Ishigami, M.; Chen, J. H.; Cullen, W. G.; Fuhrer, M. S.; Williams, E. D. Atomic structure of graphene on $\mathrm{SiO}_{2}$. Nano Lett. 2007, 7, 1643-1648.

[11] Meyer, J. C.; Geim, A. K.; Katsnelson, M. I.; Novoselov, K. S.; Booth, T. J.; Roth, S. The structure of suspended graphene sheets. Nature 2007, 446, 60-63.

[12] Konatham, D.; Striolo, A. Molecular design of stable graphene nanosheets dispersions. Nano Lett. 2008, 8, 4630-4641.

[13] Graf, D.; Molitor, F.; Ensslin, K.; Stampfer, C.; Jungen, A.; Hierold, C.; Wirtz, L. Raman imaging of graphene. Solid State Commun. 2007, 143, 44-46.

[14] Liang, M. H.; Zhi, L. J. Graphene-based electrode materials for rechargeable lithium batteries. J. Mater. Chem. 2009, 19, 5871-5878.

[15] Stankovich, S.; Dikin, D. A.; Dommett, G. H. B.; Kohlhaas, K. M.; Zimney, E. J.; Stach, E. A.; Piner, R. D.; Nguyen S. T.; Ruoff R. S. Graphene-based composite materials. Nature 2006, 442, 282-286.

[16] Blake, P.; Brimicombe, P. D.; Nair, R. R.; Booth, T. J.; Jiang, D.; Schedin, F.; Ponomarenko, L. A.; Morozov, S. V.; Gleeson, H. F.; Hill, E. W.; Geim, A. K.; Novoselov, K. S. Graphene-based liquid crystal device. Nano Lett. 2008, 8, 1704-1708.

[17] Zu, S. Z.; Han, B. H. Aqueous dispersion of graphene sheets stabilized by pluronic copolymers: formation of supramolecular hydrogel. J. Phys. Chem. C 2009, 113, 13651-13657.

[18] Wang, X.; Zhi, L.; Müellen, K. Transparent, conductive graphene electrodes for dye-sensitized solar cells. Nano Lett. 2008, 8, 323-327.

[19] Hong, W. J.; Xu, Y. X.; Lu, G. W.; Li, C.; Shi, G. Q. Transparent graphene/PEDOT-PSS composite films as counter electrodes of dye-sensitized solar cells. Electrochem. Commun. 2008, 10, 1555-1558.

[20] Zhao, L.; Zhao, L.; Xu, Y. X.; Qiu, T. F.; Zhi, L. J.; Shi, G. Q. Polyaniline electrochromic devices with transparent graphene electrodes. Electrochim. Acta 2009, 55, 491-497.

[21] Fan, F. R.; Park, S.; Zhu, Y.; Ruoff, R. S.; Bard, A. J. Electrogenerated chemiluminescence of partially oxidized highly oriented pyrolytic graphite surfaces and of graphene oxide nanoparticles. J. Am. Chem. Soc. 2009, 131, 937-939.

[22] Robinson, J. T.; Zalalutdinov, M.; Baldwin, J. W.; Snow, E. S.; Wei, Z. Q.; Sheehan, P.; Houston, B. H. Wafer-scale reduced graphene oxide films for nanomechanical devices. Nano 
Lett. 2008, 8, 3441-3445.

[23] Shan, C. S.; Yang, H. F.; Han, D. X.; Zhang, Q. X.; Ivaska, A.; Niu, L. Water-soluble graphene covalently functionalized by biocompatible poly- $L$-lysine. Langmuir 2009, 25, 12030 12033.

[24] Akhavan, O.; Ghaderi, E. Photocatalytic reduction of graphene oxide nanosheets on $\mathrm{TiO}_{2}$ thin film for photoinactivation of bacteria in solar light irradiation. J. Phys. Chem. C 2009, 113, 20214-20220.

[25] Eda, G.; Chhowalla, M. Graphene-based composite thin films for electronics. Nano Lett. 2009, 9, 814-818.

[26] Ramanathan, T.; Abdala, A. A.; Stankovich, S.; Dikin, D. A.; Herrera-Alonso, M.; Piner, R. D.; Adamson, D. H.; Schniepp, H. C.; Chen, X.; Ruoff, R. S.; Nguyen, S. T.; Aksay, I. A.; Prud'Homme, R. K.; Brinson, L. C. Functionalized graphene sheets for polymer nanocomposites. Nat. Nanotechnol. 2008, 3, 327-331.

[27] Kim, K. S.; Zhao, Y.; Jang, H.; Lee, S. Y.; Kim, J. M.; Kim, K. S.; Ahn, J. H.; Kim, P.; Choi, J. P.; Hong, B. H. Large-scale pattern growth of graphene films for stretchable transparent electrodes. Nature 2009, 457, 706-710.

[28] Paredes, J. I.; Villar-Rodil, S.; Martinez-Alonso, A.; Tascon, J. M. D. Graphene oxide dispersions in organic solvents. Langmuir 2008, 24, 10560-10564.

[29] Novoselov, K. S.; Jiang, D.; Schedin, F.; Booth, T. J.; Khotkevich, V. V.; Morozov, S. V.; Geim, A. K. Twodimensional atomic crystals. Proc. Natl. Acad. Sci. U. S. A. 2005, 102, 10451-10453.

[30] Chen, Y.; Zhang, X.; Yu, P.; Ma, Y. W. Stable dispersions of graphene and highly conducting graphene films: A new approach to creating colloids of graphene monolayers. Chem. Commun. 2009, 4527-4529.

[31] Shen, J. F.; Hu, Y. Z.; Shi, M.; Lu, X.; Qin, C.; Li, C.; Ye, M. $\mathrm{X}$. Fast and facile preparation of graphene oxide and reduced graphene oxide nanoplatelets. Chem. Mater. 2009, 21, 3514 3520

[32] Dervishi, E.; Li, Z. R.; Watanabe, F.; Biswas, A.; Xu, Y.; Biris, A. R.; Saini, V.; Biris, A. S. Large-scale graphene production by RF-cCVD method. Chem. Commun. 2009, 4061-4063.

[33] Somani, P. R.; Somani, S. P.; Umeno, M. Planar nanographenes from camphor by CVD. Chem. Phys. Lett. 2006, 430, 56-59.

[34] Worsley, K. A.; Ramesh, P.; Mandal, S. K.; Niyogi, S.; Itkis, M. E.; Haddon, R. C. Soluble graphene derived from graphite fluoride. Chem. Phys. Lett. 2007, 445, 51-56.

[35] Hernandez, Y.; Nicolosi, V.; Lotya, M.; Blighe, F. M.; Sun, Z. Y.; De, S.; McGovern, I. T.; Holland, B.; Byrne, M.; Gun'Ko, Y. K.; Boland, J. J.; Niraj, P.; Duesberg, G.; Krishnamurthy, S.; Goodhue, R.; Hutchison, J.; Scardaci,
V.; Ferrari, A. C.; Coleman, J. N. High-yield production of graphene by liquid-phase exfoliation of graphite. Nat. Nanotechnol. 2008, 3, 563-568.

[36] Stankovich, S.; Piner, R. D.; Nguyen, S. T.; Ruoff, R. S. Synthesis and exfoliation of isocyanate-treated graphene oxide nanoplatelets. Carbon 2006, 44, 3342-3347.

[37] Si, Y. C.; Samulski, E. T. Synthesis of water soluble graphene. Nano Lett. 2008, 8, 1679-1682.

[38] McAllister, M. J.; Li, J. L.; Adamson, D. H.; Schniepp, H. C.; Abdala, A. A.; Liu, J.; Herrera-Alonso, M.; Milius, D. L.; Car, R.; Prud'homme, R. K.; Aksay, I. A. Single sheet functionalized graphene by oxidation and thermal expansion of graphite. Chem. Mater. 2007, 19, 4396-4404.

[39] Schniepp, H. C.; Li, J. L.; McAllister, M. J.; Sai, H.; Herrera-Alonso, M.; Adamson, D. H.; Prud'homme, R. K.; Car, R.; Saville, D. A.; Aksay, I. A. Functionalized single graphene sheets derived from splitting graphite oxide. $J$. Phys. Chem. B 2006, 110, 8535-8539.

[40] Xu, Y.; Bai, H.; Lu, G.; Li, C.; Shi, G. Flexible graphene films via the filtration of water-soluble noncovalent functionalized graphene sheets. J. Am. Chem. Soc. 2008, 130, 5856-5857.

[41] Niyogi, S.; Bekyarova, E.; Itkis, M. E.; McWilliams, J. L.; Hamon, M. A.; Haddon, R. C. Solution properties of graphite and graphene. J. Am. Chem. Soc. 2006, 128, 7720-7721.

[42] Li, D.; Mueller, M. B.; Gilje, S.; Kaner, R. B.; Wallace, G. $\mathrm{G}$. Processable aqueous dispersions of graphene nanosheets. Nat. Nanotechnol. 2008, 3, 101-105.

[43] Li, L. X.; An, B. G.; Nishihara, H.; Shiroya, T.; Aikyo, H.; Isojima, T.; Yamamoto, M.; Kyotani, T. Water-dispersible "carbon nanopods" with controllable graphene layer orientation. Chem. Commun. 2009, 4554-4556.

[44] Pasricha, R.; Gupta, S.; Srivastava, A. K. A facile and novel synthesis of Ag-graphene-based nanocomposites. Small 2009, 5, 2253-2259.

[45] Wang, X. R.; Tabakman, S. M.; Dai, H. Atomic layer deposition of metal oxides on pristine and functionalized graphene. J. Am Chem. Soc. 2008, 130, 8152-8153.

[46] Muszynski, R.; Seger, B.; Kamat, P. V. Decorating graphene sheets with gold nanoparticles. J. Phys. Chem. C 2008, 112, 5263-5266.

[47] Seger, B.; Kamat, P. V. Electrocatalytically active grapheneplatinum nanocomposites. Role of 2-D carbon support in PEM fuel cells. J. Phys. Chem. C 2009, 113, 7990-7995.

[48] Kou, R.; Shao, Y. Y.; Wang, D. H.; Engelhard, M. H.; Kwak, J. H.; Wang, J.; Viswanathan, V. V.; Wang, C. M.; Lin, Y. H.; Wang, Y. G; Aksay, I. A.; Liu, J. Enhanced activity and stability of Pt catalysts on functionalized graphene sheets for electrocatalytic oxygen reduction. Electrochem. Commun. 
2009, 11, 954-957.

[49] Yoo, E.; Okata, T.; Akita, T. Kohyama, M.; Nakamura, J.; Honma, I. Enhanced electrocatalytic activity of Pt subnanoclusters on graphene nanosheet surface. Nano Lett. 2009, 9, 2255-2259.

[50] Xu, C.; Wang, X. Fabrication of flexible metal-nanoparticle films using graphene oxide sheets as substrates. Small 2009, $5,2212-2217$.

[51] Lu, G. H.; Mao, S.; Park, S.; Ruoff, R. S.; Chen, J. H. Facile, noncovalent decoration of graphene oxide sheets with nanocrystals. Nano Res. 2009, 2, 192-200.

[52] Zhou, X. Z.; Huang, X.; Qi, X.; Wu, S. X.; Xue, C.; Boey, F. Y. C.; Yan, Q. Y.; Chen, P.; Zhang, H. In situ synthesis of metal nanoparticles on single-layer graphene oxide and reduced graphene oxide surfaces. J. Phys. Chem. C 2009, 113, 10842-10846.

[53] Kong, B. S.; Geng, J. X.; Jung, H. T. Layer-by-layer assembly of graphene and gold nanoparticles by vacuum filtration and spontaneous reduction of gold ions. Chem. Commun. 2009, 2174-2176..

[54] Hassan, H. M. A.; Abdelsayed, V.; Khder, A. R. S.; AbouZeid, K. M.; Terner, J.; El-Shall, M. S.; Al-Resayes, S I.; El-Azhary, A. A. Microwave synthesis of graphene sheets supporting metal nanocrystals in aqueous and organic media. J. Mater. Chem. 2009, 19, 3832-3837.

[55] Scheuermann, G. M.; Rumi, L.; Steurer, P.; Bannwarth, W.; Mülhaupt, R. Palladium nanoparticles on graphite oxide and its functionalized graphene derivatives as highly active catalysts for the Suzuki-Miyaura coupling reaction. J. Am. Chem. Soc. 2009, 131, 8262-8270.

[56] Li, Y. M.; Tang, L. H.; Li, J. H. Preparation and electrochemical performance for methanol oxidation of Pt/graphene nanocomposites. Electrochem. Commun. 2009, 11, 846-849.

[57] Yuge, R.; Zhang, M. F.; Tomonari, M.; Yoshitake, T.; Iijima, S.; Yudasaka, M. Site identification of carboxyl groups on graphene edges with $\mathrm{Pt}$ derivatives. ACS Nano 2008, 2, 1865-1870.

[58] Yang, X. Y.; Zhang, X. Y.; Ma, Y. F.; Huang, Y. S.; Wang, Y. S.; Chen, Y. Superparamagnetic graphene oxide- $\mathrm{Fe}_{3} \mathrm{O}_{4}$ nanoparticles hybrid for controlled targeted drug carriers. $J$. Mater. Chem. 2009, 19, 2710-2714.

[59] Goncalves, G.; Marques, P. A. A. P.; Granadeiro, C. M.;
Nogueira, H. I. S.; Singh, M. K.; Gracio, J. Surface modification of graphene nanosheets with gold nanoparticles: The role of oxygen moieties at graphene surface on gold nucleation and growth. Chem. Mater. 2009, 21, 4796-4802.

[60] Li, F. H.; Yang, H. F.; Shan, C. S.; Zhang, Q. X.; Han, D.; Ivaska, A.; Niu, L. The synthesis of perylene-coated graphene sheets decorated with Au nanoparticles and its electrocatalysis toward oxygen reduction. J. Mater. Chem. 2009, 19, 40224025 .

[61] Severin, N.; Kirstein, S.; Sokolov, I. M.; Rabe, J. P. Rapid trench channeling of graphenes with catalytic silver nanoparticles. Nano Lett. 2009, 9, 457-461.

[62] Hummers, W. S.; Offeman, R. E. Preparation of graphitic oxide. J. Am. Chem. Soc. 1958, 80, 1339.

[63] Shen, J. F.; Hu, Y. Z.; Li, C.; Qin, C.; Ye, M. X. Synthesis of amphiphilic graphene nanoplatelets. Small 2009, 5, 82-85.

[64] Jeng, K. T.; Chien, C. C.; Hsu, N. Y.; Yen, S. C.; Chiou, S. D.; Lin, S. H.; Huang, W. M. Performance of direct methanol fuel cell using carbon nanotube-supported $\mathrm{Pt}-\mathrm{Ru}$ anode catalyst with controlled composition. J. Power Sources 2006, 160, 97-104.

[65] Li, W. Z.; Liang, C. H.; Zhou, W. J.; Qiu, J. S.; Li, H. Q.; Sun, G. Q.; Xin, Q. Homogeneous and controllable Pt particles deposited on multi-wall carbon nanotubes as cathode catalyst for direct methanol fuel cells. Carbon 2004, 42, 436-439.

[66] Murugan, A. V.; Muraliganth, T.; Manthiram, A. Rapid, facile microwave-solvothermal synthesis of graphene nanosheets and their polyaniline nanocomposites for energy storage. Chem. Mater. 2009, 21, 5004-5006.

[67] Hull, R. V.; Li, L.; Xing, Y. C.; Chusuei, C. C. Pt nanoparticle binding on functionalized multiwalled carbon nanotubes. Chem. Mater. 2006, 18, 1780-1788.

[68] Yang, H. F.; Li, F. H.; Shan, C. S.; Han, D. X.; Zhang, Q. X.; Niu, L.; Ivaska, A. Covalent functionalization of chemically converted graphene sheets via silane and its reinforcement. J. Mater. Chem. 2009, 19, 4632-4638.

[69] Li, F. L.; Song, J. F.; Yang, H. F.; Gan, S. Y.; Zhang, Q. X.; Han, D. X.; Ivaska, A.; Niu, L. One-step synthesis of graphene $/ \mathrm{SnO}_{2}$ nanocomposites and its application in electrochemical supercapacitors. Nanotechnology 2009, 20, 455602.

[70] Si, Y. C.; Samulski, E. T. Exfoliated graphene separated by platinum nanoparticles. Chem. Mater. 2008, 20, 6792-6797. 